\title{
Repercussão do tratamento contra verminose gastrointestinal sobre o quadro eritrocitário e leucograma de ovinos com anemia verminótica
}

Carlos Lima Pereira Junior', Glauco Dente Gurtler, Adrielle Levatti, Melina Marie Yasuoka, Daniela Becker Birgel, Eduardo Harry Birgel Junior

Departamento de Medicina Veterinária, Faculdade de Zootecnia e Engenharia de Alimentos, Universidade de São Paulo (USP), Pirassununga, SP, Brasil

*Autor correspondente

e-mail: jrlimamoncao@hotmail.com

\section{Resumo}

O Haemonchus contortus é um nematódeo de grande importância aos pequenos ruminantes e sua ação hematófaga pode levar a um processo anêmico crônico, ocorrendo depleção de reservas de ferro a um grau extremo. 0 objetivo deste projeto foi avaliar a repercussão de diferentes tratamentos contra verminose gastrointestinal sobre o quadro eritrocitário e leucograma de ovinos com anemia verminótica. Foi realizado exame clinico, hemograma e contagem de ovos em 36 ovelhas, com mais de 24 meses, oriundas de propriedade da região de Pirassununga/SP. Os animais foram alocados em três grupos experimentais (1, 2 e 3), sendo escolhidos apenas aqueles que apresentavam anemia intensa, decorrente da infestação parasitária. 0 grupo 1 foi tratado com antiparasitários (Monepantel: 2,5 mg/kg de peso vivo, em dose única, por via oral e Albendazole: $20 \mathrm{mg} / \mathrm{Kg}$ de peso vivo, em intervalos de 15 dias, por via oral). No grupo 2, além dos antiparasitários, foi aplicado Flunixin Meglumine (2,0 mg/Kg de peso vivo, durante três dias, por via intramuscular) e Enrofloxacino (2,5 $\mathrm{mg} / \mathrm{Kg}$ de peso vivo, durante cinco dias, por via intramuscular). No grupo 3, além dos antiparasitários, foi aplicado Ferro Dextrano (10,0 mg/Kg de peso vivo, em intervalos de três dias, totalizando quatro aplicações, por via intramuscular). Os animais foram acompanhados por 60 dias para avaliação hematológica e coproparasitológica nos seguintes momentos: antes do tratamento, $1^{\circ}, 3^{\circ}, 7^{\circ}, 10^{\circ}, 15^{\circ}, 30^{\circ}, 45^{\circ}$ e $60^{\circ}$ dia. Verificou-se que, em termos médios, houve predomínio de anemia do tipo normocítico e normocrômico. Nos grupos de animais acompanhados, o grupo 3 foi o primeiro a reestabelecer seus parâmetros hematológicos (D15), se comparado aos demais grupos (D30). Sobre o leucograma, evidenciou-se normoleucocitemia com existência de neutrofilia sem desvio à esquerda, linfopenia e eosinopenia. Esses resultados evidenciam que as alterações no leucograma de animais com anemia verminótica não se devem somente à perda crônica de sangue, pois se por um lado a linfopenia 
e eosinopenia poderiam ser creditados ao processo crônico, por outro, a normoleucocitemia e valores de neutrófilos dentro da normalidade ou aumentados (como observado nos ovinos com anemia grave) não direcionam a esta condição. Foi observada ocorrência da inversão do padrão leucocitário, que muda de predominantemente linfocitário para neutrofílico e acentua-se com o aumento da intensidade do processo anêmico. A diminuição do numero de linfócitos circulantes seria consequência de sua provável migração para a mucosa abomasal. Entre os grupos de animais acompanhados, diagnosticados com infecção por Haemonchus contortus, o grupo 03 foi aquele que mais rapidamente zerou seu opg (D10). 